those who may not choose to access professionally led services to receive support and information following bereavement. Referrals are triaged to the service via Newham Psychological Services who partner us in providing this service. The service is mainly operated by volunteers, with only two members of staff dedicated to the service on a part-time basis.

Findings and Recommendations We evaluate the impact of our service by measuring several factors including how the support has affected service user's lives.

Conclusion The services is in its first year, of three commissioned, but has had a strong start up with a high number of volunteers trained and 'active'. The level of uptake will allow us to find out the gaps in service provision/uptake and the need for informal support. This model could be replicated in other boroughs if the need and response is supported.

\section{P40 A HOSPICE CHAPLAINCY APPROACH TO COMMUNITY OUTREACH: BUILDING END OF LIFE GROUPS WITHIN FAITH COMMUNITIES}

Sr Hilary Thompson, Vivi Boucher. St Joseph's Hospice, Hackney, London, UK

\subsection{6/bmjspcare-2013-000591.62}

Introduction This innovative piece of Hospice Chaplaincy outreach is in its infancy. It is a listening project concentrating on multi faith communities in a richly diverse multi ethnic, multicultural inner city borough. The focus is on End of Life Care and Hospice services.

Aims This project aims to build long lasting relationships between local faith communities and the Hospice. It is organic and will develop according to the expressed needs of the stakeholders.

Method A local council map of places of worship was divided into four smaller areas and a project plan developed. Faith leaders in the first area were visited. Several introductory workshops were held in the Hospice. The Chaplain was invited to speak and give workshops in some faith communities. A training programme for volunteers to support End of Life Groups in faith communities was initiated. Work in area one is being sustained while visits to faith leaders begin in area two.

Results All thirty five faith leaders in area one were visited and invited into the Hospice for an introductory workshop. Twenty seven attended. A significant number had not met before. A second workshop was requested and several requested talks and workshops to be given to their faith communities. This has resulted in the development of a series of workshops based on the needs of these faith groups.

Discussion So far the results are consistent with the aims. Faith leaders meeting for the first time were able to explore possibilities of working more closely. Several have come into the Hospice to attend other events. End of Life groups are beginning in faith communities. Death is being discussed.

Conclusion Information given is often based on professional assessment of what is wanted, this ensures that we listen and respond to articulated needs. Working systematically with smaller groupings embeds the project in faith communities.

\section{P41 ENGAGING OUR LOCAL COMMUNITIES}

Celia Pyke-Lees, Laura Parker. St Michael's Hospice, St Leonards on Sea, UK

10.1136/bmjspcare-2013-000591.63

'Creativity is contagious. Pass it on' Albert Einstein
Rooted in creativity Our area is filled with creative spirits, working away at their craft creating some truly stunning pieces. These artisans will often say that their work is good for the soul, working with their hands and heart with stunning results. At the Hospice we believe in holistic care, focusing on the individual, their soul and the things that matter to them. We believe that by adopting this focus it not only helps the individual but also the people that surround them, their family and friends. So as we started to look to ways to engage our more rural communities we decided to pair these two philosophies and host an event that was good for everyone's soul.

Create. Make. Bake was born.

The concept behind Create. Make. Bake is simply to bring together local artisans, with skills such 3D weaving, upholstery, jewellery making or bread making, to share their skill, knowledge and expertise. Artisans held workshops, demonstrations and talks and let the visiting public have a go. Our Trading Warehouse supplied a range of materials and a Pop-Up shop.

Create. Make. Bake. is a relaxed affair. No formal table plan, no standing behind trestle tables and no entrance or exhibiting fee. A free and informal event that targets local communities, engages the Hospice with a new audience and communicates the services that we can provide.

So, how did it turn out? Well... 16 tables with different artisans. 15 amazing raffle prizes. Over a 100 people through the door. People learnt, shared and, most importantly, enjoyed a day to remember with the Hospice. There was positive feedback: 'Had a great time today and thought the event was very inspirational.',

Will it become an annual event? It's been booked in the diary already!

\section{P42 MEDITATION: FROM HOSPICE TO COMMUNITY - FROM THERAPY TO LIFE SKILL}

lan Dewar. St Catherine's Hospice, Preston, UK

\subsection{6/bmjspcare-2013-000591.64}

Introduction Programmes are developed in hospices to meet the needs of patients and have the potential to be life changing for people in the wider community. This project stemmed from work with patients on using meditation (mindfulness) as a therapeutic tool and extended outwards into the wider community.

Aim Bring together experience and praxis of work with patients, extract life lessons and turn these into life skills for non patients. Methods Combining the experience of the facilitator (20 years of teaching meditation) and the insights gained from working with patients, a 6 week introductory course was developed for the wider community to buy into. Each session is 1.5 hours in length and there is an upper limit of 10 people per course.

Data is gathered verbally as the course progresses and the course is flexible by design so that changes in emphasis can take place according to group need. Feedback sheets are issued at the end of the 6 week course.

Results The course for non-patients is now into its fourth programme, numbers are growing -4 on the first course, 10 on the third - and it is generating regular publicity for the hospice. At $£ 99$ per person per course for non-patients it is also generating income. More significantly feedback indicates that people are coping better with anxiety, changing attitudes to life situations, volunteering for the hospice and many report continuing to practise after the completion of the course. 
Discussion Expected and unexpected are words that relate to this project. Expected reductions in anxiety where met. One of the most surprising things (needing further research) is where participants reported improvements in physical awareness and health as a result of meditation practice.

Conclusion Meditation (mindfulness) offers a model of how certain hospice skills are eminently transferable to different settings enhancing the hospices model of care, community engagement and profile.

\section{P43 THE USE OF SOCIAL MEDIA BY UK HOSPICES: REVIEW AND DISCUSSION}

${ }^{1}$ Eleanor Kleszzz, ${ }^{1,2}$ Carolyn Campbell. ${ }^{1}$ Cornwall Hospice Care, St Austell, UK, ${ }^{2}$ Peninsula College of Medicine and Dentistry, Plymouth, UK

\subsection{6/bmjspcare-2013-000591.65}

Background With more than $65 \%$ of adults actively using social media each week it is important to ensure that hospices are developing new ways to engage with this population group to encourage fundraising and provide support to patients and carers. Social media provide exciting opportunities for hospices to widen their influence and activity, but also raise practical and ethical issues which must be addressed.

Methods This research appraised 150 hospice websites in England and Wales to determine the prevalence of social media and how it is being used to engage, educate and support hospice users, volunteers and staff. Numbers of users and type of use (fundraising, support, awareness raising) were recorded and factors such as prominence on website explored. Social media sites were also searched for links to hospice and palliative care issues. Results In total, 35\% of hospice websites used Facebook and $33 \%$ used Twitter to communicate with the public, 28\% of websites accessed did not use any form of social media. The majority of social media sites were used to encourage and provide information regarding fundraising. Very few websites used a forum, an opportunity for hospices to provide support to hospice users whilst also educating and encouraging fundraising in a more secure environment. The extended search of social media sites highlighted areas of discussion, support and awareness raising distinct from and not tapped into by hospice sites.

Discussion The rewards and disadvantages of forum use for hospices are explored alongside recommendations for improving public awareness of the hospice social media sites. To date, UK hospices are underusing social media both in volume of traffic and scope (overwhelmingly for fundraising only). This leaves hospices self-excluding from much of the potential of social media to inform, support and debate, and at risk of being left behind.

\section{Education, training and research}

\section{P44 THE INTRODUCTION OF A PATIENT EDUCATION PROGRAMME INTO A HOSPICE DAY SERVICE}

Chris Benson. St. Peter's Hospice, Bristol, UK

\subsection{6/bmjspcare-2013-000591.66}

At a time when hospice care is being scrutinised by commissioners this small study evaluates the implementation of an education programme in a Day Hospice and the impact this had on patients living with life limiting illness.
Education for patients near end of life appears to have received minimal research attention. Wider investigation of the needs of these patients reveals that the impact of illness robs them of their sense of self and autonomy (Johnston 2004), and opportunities to self-care and self-manage can be limited by paternalism (Cottrell 2008, Jackson 2006).

This programme offered patients the opportunity to attend facilitated educational discussion groups such as medicine management, coping with anxiety and breathlessness, and planning ahead for death and to participate in group relaxation and exercise sessions

A case study methodology allowed the use of mixed methods to collect data from three sources; patients, using diaries and transcribed interviews; staff delivering the programme using a focus group; and professionals referring to the service using a questionnaire.

Findings revealed that patients had motivation and capacity to participate and learn however ill they were, demonstrating their desire to be acknowledged as 'active and participating citizens' (Kendall et al 2007:524). Patients also experienced an increase in self-esteem and confidence resulting from the programme.

Staff delivering the programme reported an increase in their confidence through facilitating discussion groups and were challenged in relation to their preconceived ideas about what individual patients may want to learn.

Other findings related to the ability to promote the service to a wider group of potential patients.

This small study demonstrates the potential for increased 'self-care' when an education programme is introduced within a Day Hospice setting. This may positively influence potential commissioners to the service and raise the profile of Day Services as part of Hospice Care.

\section{P45 COMMUNICATING WITH CARE, IN AN EVER INCREASINGLY COMPLEX WORLD}

Janet Dunphy. Kirkwood Hospice, Huddersfield, England

10.1136/bmjspcare-2013-000591.67

Background Within the last decade, numerous white papers have been published to improve care for palliative care patients. The principle of effective communication is at the heart of clinical practice and professional codes. Often communication training programmes are expensive, elitist or inaccessible. It is a challenge to develop a workforce in the current climate and demands of biological and sociological developments.

The more complex healthcare becomes, the more important it becomes to keep it simple.

Aim To improve the confidence and competence of the workforce who will communicate with palliative care patients.

Approach Design \& delivery of innovative, accessible, multiprofessional education. The two day programme includes pre and post training interviews in order to provide meaningful, individual assessment and feedback. The teaching styles are both negotiated and didactic. The programme provides an opportunity for professionals to observe and participate in scenarios which demonstrate key and difficult issues involved in communication. The teaching team consists of 'Jobbing experts' who have undergone advanced communication skills training, specialist clinicians who share the many and various scripts that lie in their memories. Formative assessments include a reflective essay, 